\title{
Interface models coupling adhesion and friction
}

\author{
Michel Raous \\ LMA, 31, chemin Joseph Aiguier, 13402 Marseille Cedex 20, France \\ Received ${ }^{* * * * *}$; accepted after revision +++++ \\ Presented by
}

\begin{abstract}
Interface models coupling friction and adhesion, where adhesion is regarded as interface damage, are briefly reviewed. The most widely used cohesive zone models are presented and discussed. A general framework for these laws, recently developed by Del Piero and Raous in the form of a unified model, is outlined. As an example, it is here established that the RCCM (Raous-Cangémi-Cocou-Monerie) model is a specific case in this general framework. The variational formulation and some associated solvers are briefly recalled in the context of non smooth mechanics in the cases of both quasi-static and dynamic problems. A few examples in various fields of application are given. Lastly, some open problems and ongoing researches in this field are presented and discussed.
\end{abstract}

To cite this article: M. Raous, C. R. Mécanique 333 (2010).

\section{Modles d'interface couplant adhésion et frottement}

Résumé On passe ici en revue de manière concise les modèles d'interface couplant frottement et adhésion, où l'adhésion est considérée comme un endommagement d'interface. Les modèles de zones cohésives les plus utilisés sont présentés et discutés. Un cadre général pour ces lois est donné sous la forme d'une formulation unifiée récemment proposée par Del Piero et Raous. Comme exemple d'application, on établit que la loi RCCM (Raous-Cangémi-Cocou-Monerie) est un cas particulier de cette formulation générale. Les formes variationnelles et quelques méthodes de résolution associées sont rappelées dans le contexte de la mécanique non régulière à la fois pour des problèmes quasi-statiques et pour des problèmes dynamiques. Quelques exemples dans des domaines d'application variés sont donnés. Enfin, quelques problèmes ouverts et des recherches en cours dans ce champ thématique sont évoqués.

Pour citer cet article: M. Raous, C. R. Mécanique 333 (2010).

Key words: Contact; Adhesion; Friction; Interface ; Non-smooth mechanics

Mots clés: Contact; Adhésion; Frottement; Interface; Mécanique non régulière 


\section{Introduction}

It is proposed in this study to briefly review Cohesive Zone Models (CZM) and some more general models combining unilateral contact, adhesion and friction. Adhesion is taken to be a form of interface damage. The paper is divided into four parts.

The most widely used cohesive zone models are first presented and discussed. In the second part, an axiomatics for adhesive interfaces, based on the unified model recently proposed by Del Piero and Raous in [22], is presented.

In the third part, after choosing appropriate basic constitutive functions and dissipation potentials, it is established that the RCCM model [72] [73] [74] is a specific case in this general framework. The variational formulation associated to this law and various solvers taking its non-smooth character into account are recalled for dealing with both quasi-static and dynamic problems (no regularization procedure is used). A few examples in various fields of application are given.

In the last section, some open problems and ongoing researches in the field are mentioned and discussed.

\section{Interface behavior laws}

\subsection{A brief panorama}

The mechanics of surfaces differs substantially from the contact mechanics approach, where the interface conditions between rigid or deformable solids are usually described in terms of unilateral and friction conditions. Surface mechanics focuses on more complex behavior and positive traction forces have in particular to be simulated. These traction forces can be of very diverse origins; they can be due, for instance, to either the thermo-physical effects occurring during the manufacture of the material, the physico-chemical effects generated by gluing and assembling processes, or the cohesive effects associated with ductile failure. Adhesion can be involved on various scales: that of structures, heterogeneous materials, grain boundaries, oxide layers, coatings, etc. More recently, micro-mechanics and nano-mechanics problems have shown that it could be essential to simulate the adhesive effects.

Email address: raous@lma.cbrs-mrs.fr (Michel Raous). 
Many models for adhesive interfaces have been developed since the 60's. Most of them have focused on the cohesive zone models in the context of fracture mechanics. The pioneer studies in the field were those by Dugdale [25], Barenblatt [6], Needleman [60] [61] [62], Needleman and Rosakis [63], Tvergaard [87], Tvergaard and Hutchinson [88][89] and Xu and Needleman [93]. Some authors have recently introduced local considerations into models of this kind (see for example the model by Brinckmann and Siegmund [9] based on dislocation theory). Both quasi-static and dynamic behavior have been considered (see for example Costanzo and Walton [20]).

On the other hand, many studies have been published on the adhesive interfaces involved in composite materials. Some of these studies have dealt with local effects occurring between fiber and matrix in order to simulate the fiber debonding processes (Raous et al. [73] [55] [74], Chaboche et al [19], Talon and Curnier [83]) or were intended for homogenization purposes (Michel and Suquet [53]). Other authors have simulated global effects such as delamination (Allix et al [2], Freddi and Fremond [30], Samimi et al [79]) and peeling (Nguyen and Levy [64]). In [85], Stupkiewicz presented a model based on asperity deformation considerations in order to take the micro-dilatancy into account. For polymer coating delamination, large displacement formulation was developed in Geers' group in order to account for local effects such as the interfacial fibrillation ([8]).

Geers' group has also focused on the thermo-mechanical adhesive zone at inter-granular interfaces in order to describe the evolution of the thermal field in coating layers subjected to thermic shocks $([65])$.

Interface modeling has been carried out in many other fields besides the mechanics of materials and structures. In Civil Engineering for example, studies have been conducted on interfaces in reinforced concrete (steel/concrete interfaces) and that of piles (pile/ground interfaces) (Raous et al [76] [84], Wriggers et al [81] and Peerlings et al [69]) and masonry (Fouchal et al [29], Alfano and Sacco [5], Acary et al [1] [43]). Multilevel interface models have been also developped for quasi-britle masonry by Rekik-Lebon [77].

In Geophysics, the choice of behavior laws for modeling the interfaces between tectonic plates along faults is a key point for studying the nucleation of earthquakes. The laws most commonly adopted in this context are the "rate and state" and the "slip weakening" laws (Campillo and Ionescu [10]; Rice and Ruina [78]; Uenishi and Rice [90]), and laws relating friction to adhesion are now under development (Festa et al. [27] [28]).

Another class of studies concerns the general formulation of constitutive laws for interfaces or contact between distinct rigid or deformable bodies involving unilateral conditions, friction and adhesion. These models are based on the concept of intensity of adhesion, first introduced by Frémond [31] [32], which is similar to the notion of volumic damage [34] [46], extended to interfaces. When the adhesion is complete, this intensity is taken to be equal to one and when the adhesion is totally disrupted, its value is taken to be equal to zero. Models on these lines have been based on thermo-mechanical considerations, 
and the viscous dissipation is sometimes taken into account (Frémond et al [31] [32] [30]; Raous et al [71] [73] [74]; Chaboche et al [19]; Talon and Curnier [83]). These models are quite general. They can be associated with any kind of loading conditions (including alternating loads) whereas cohesive zone models are based on the assumption that the normal effects predominate (and that friction therefore does not need to be taken into account) and the evolutions are generally taken to be monotonous.

To conclude this brief review, the JKR model, developed by Johnson-KendallRoberts ([39] [41] [40]) and Sperling ([82]) for the contact between a rigid sphere and a semi-infinite plane, is worth mentioning. This is an analytical model based on the Hertz theory, which was improved by analytical computations in which a correcting load controlled by the adhesive energy was applied. In Tribology, many authors have used either this model or a variant to study contact with polymers or viscoelastic bodies (see for example Maugis and Barquins [51] [52] [7], Greenwoods [37]). Among other analytical or semi-analytical studies, a model for molecular or capillarity adhesion has been developed by Goryacheva-Makhovskaya [36].

The present review is by no means exhaustive, and many other references can be found in the papers cited above, as well as in the doctoral theses by Monerie [55], Perales [67] and Schryve [80], for instance.

\subsection{The main classes of adhesive interface laws}

In most theories, the interfaces are assumed to show elastic behavior while the loss of adhesion is described by a damage variable, which Frémond called the intensity of adhesion [31] [32]. The interface is taken to be a material boundary with a null thickness, a thermo-mechanical frame is provided and the intensity of adhesion constitutes an extra state variable, with which a thermodynamic force is associated [31] [32] [71] [73]. As regards the tangential components of the relative displacements, the initial adhesion has been sometimes assimilated to a static friction coefficient, which starts to decrease when sliding occurs. Intrinsic models are those including an initial compliance and the extrinsic ones are those without. The main classes of adhesive interface laws can be summarized under the following headings.

- Unloading and cycling behavior

Adhesion was initially studied only under monotonous loading conditions, and the problem of the reversibility of the response of the interface was therefore not addressed. The non interpenetration condition was therefore not included to control the normal displacement (or the gap) and the behavior during reverse normal and tangential displacements did not have to be specified. This was generally so in the case of cohesive zone models in fracture mechanics and that of the interface laws developed in the field of 
Geomechanics, for example.

In cases where unloading evolution is taken into account, the unilateral conditions can be described in terms of the strict Signorini conditions or using either compliance or penalization methods. The adhesion can be satisfactorily defined within the concept of elastic behavior with damage of the interface, applied to both normal and tangential components. The behavior of the tangential components is more complex, because when friction is included in the model, the tangential force has to cross the Coulomb cone before reverse sliding occurs.

- Adhesion reversibility

Studies on cyclic behavior have often implicitly assumed damage to be irreversible. One exception to this generally accepted rule is the recoverable or healing adhesion model recently developed by Raous, Schryve and Cocou [80] [75] [18], in which the adhesion can be partly or completely recovered when contact is restored after a complete separation. Models of this kind can be used to describe forces acting without contact such as Van der Waals effects [80].

- Dissipation energies

This the key point in these models. All these models are based on the concept of damage dissipation, although in some cases, this is not explicitly stated.

It has been noted in [58] in the case of the pull-out of a single fiber in a composite material, that the decohesive energy parameter is much more important than the shape of the stress/displacement curves. However, Valoroso and Champaney have shown in [91] the effects of the shape of the contact displacement/force relationship on the solutions in various cases: a bilinear model, the Allix-Ladeveze model and an exponential model were used in various examples (end-notched flexure - ENF, mixed-mode flexure - MMF) and the results were compared with experimental data. The shape is also of great importance for the stability analysis and the possible occurrence of jumps, as discussed below in Section 5 .

Apart from the damage dissipation, the other source of dissipation is obviously the friction, although many models (such as the cohesive zone models in fracture mechanics) have not taken this factor into account, as shown in Fig. 2 . The friction can be introduced either progressively (see Fig.4), or suddenly, and it can even sometimes be sequential (see Fig. 3).

Lastly, viscous dissipation has been included in only a few models such as the RCCM model [73] and in the study by Chaboche [19] where it is suggested that viscous dissipation can be used for numerical regularization purposes. It is worth noting that viscous dissipation is also present in rate and state dependent laws such that developed by Dieterich [23], where one of the parameters in the function defining the dependence of the friction on the sliding velocity is itself time-dependent. 
- Relating tangential and normal effects

How to relate normal and tangential effects is a problem which has often been underestimated. This is mainly because one of the directions predominates in many applications. The choice of a single state variable means that damage to the interface can be due to either a normal or a tangential load. It was established in [22] that in the presence of both normal and tangential deformations, the constitutive functions cannot be determined by performing two separate loading experiments, one under normal and another one under tangential deformation, but that a single diagonal experiment has to be conducted.

\subsection{Some classical interface laws}

Here we present a few examples of classical interface behavior laws. Let us consider contact between rigid bodies or equivalently, a point to point relationship between the two faces at an interface. We take $u$ to denote the relative displacement (i.e. the gap) and $R$ to denote the contact force, of which $\left(u_{n}, u_{t}\right)$ and $\left(R_{n}, R_{t}\right)$ are the normal and tangential components, respectively. The evolution of the contact force versus the relative displacement is given in the figures below based on results published by various authors.

- Cohesive zone models for normal and monotonous loading conditions These models are mainly used to simulate the progression of ductile cracks and only normal displacements are therefore taken into account and the loads are assumed to be monotonically increasing. The evolution of the normal contact force versus the gap, given in Fig.1, is based on the models by Barenblatt [6], Dugdale [25] and Needleman [60].

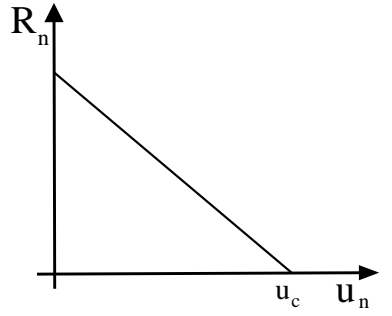

(a) Barenblatt [6]

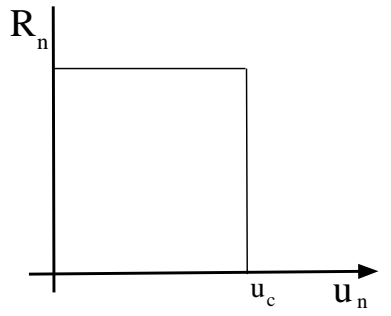

(b) Dugdale [25]

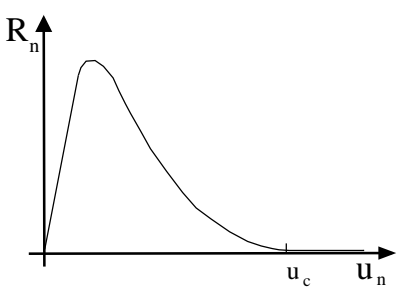

(c) Needlman [60]

Figure 1. Adhesive models for normal and monotonous loading conditions

- Adhesive tangential effects during tangential displacements

The adhesion on shear effect was first included in these models in the 70's (Palmer and Rice [66]). In the 80's, Frémond [31] [32] introduced the notion of the intensity of adhesion. As shown in Fig. 2, some authors have not taken the friction into account at all (Tvergaard and Hutchinson [88]) and 
(Xu-Needleman [93]).

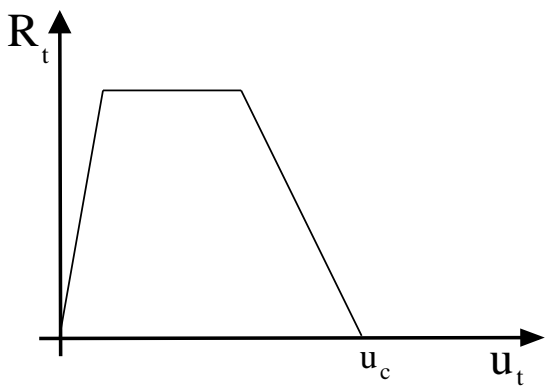

(a) Tvergaard-Hutchinson [88]

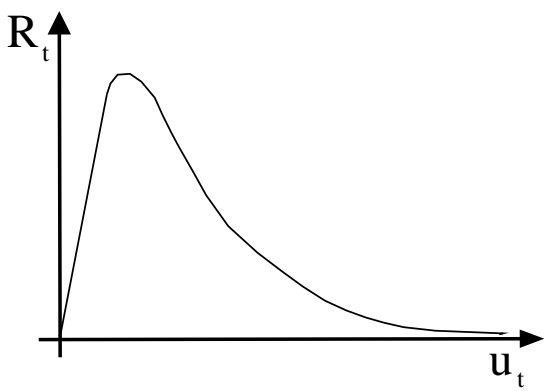

(b) Xu-Needlman [93]

Figure 2. Frictionless adhesive models for tangential loading conditions

Up to the 90's, most of these models dealt only with monotonous evolutions. Some more general loading conditions were taken into account in the model by Tvergaard [87] where adhesion and friction were modeled sequentially as shown in Fig. 3.

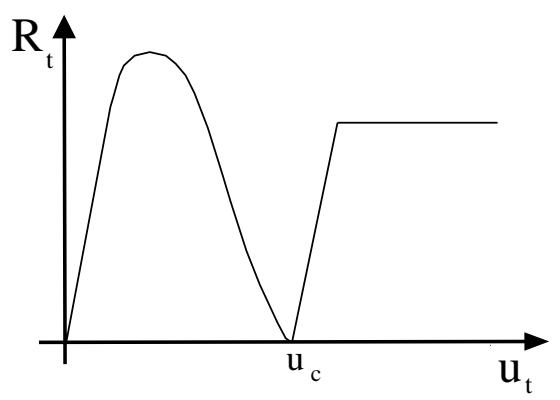

Figure 3. Adhesion and friction in the Tvergaard's model [87]

Many models coupling adhesion and friction with a smooth transition have been more recently published . Two examples are given in Fig. 4: (a) RCCM [73]); (b) Chaboche [19].

The underlying laws are obviously more complex in this case. When a reverse normal displacement is applied, the behavior is still elastic and the new value of the stiffness depends on the damage, which is evaluated by the intensity of adhesion. Unilateral conditions prevent any inter-penetration from occurring between the two edges of the interface (non penetration conditions are sometimes regularized by applying a penalization procedure). When a reverse tangential force is applied, the Coulomb threshold $\left(\mu R_{n}\right)$ has to be reached before reverse tangential sliding can occur (the Coulomb cone has to be crossed).

- Adhesion, friction and viscous dissipation

Some authors recently introduced a viscous dissipation term into the description of the interface behavior ([73] [30] [19] [46]). The normal behavior 


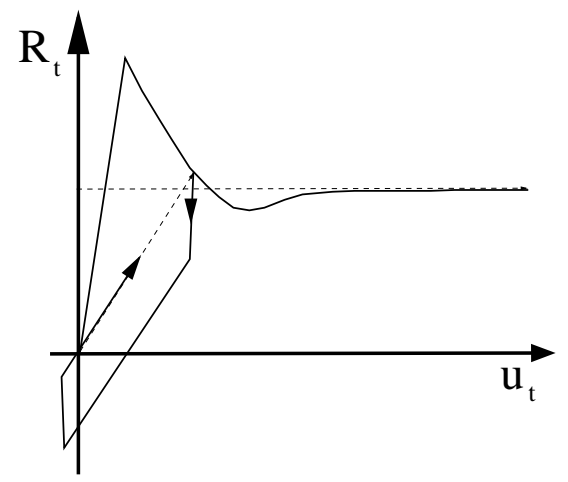

(a) RCCM with no viscosity [73]

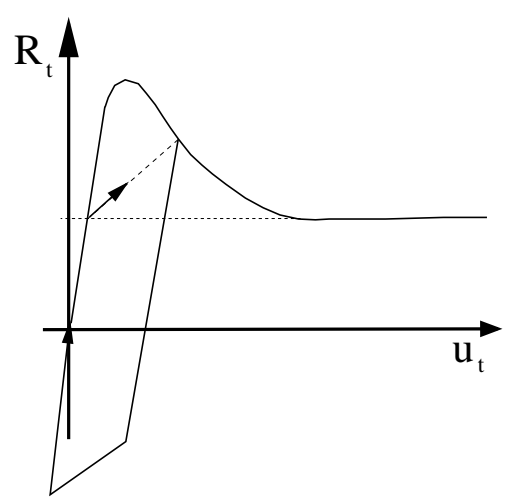

(b) Chaboche [19]

Figure 4. Adhesive models with friction and without viscosity under tangential loading conditions

with the RCCM model including viscosity is presented in Fig. 5 (a). The behavior depends here on the velocity of the loading process. In the case where the load remains constant for a while during a cycle, a creep process occurs: the intensity of adhesion goes on decreasing although the contact force remains constant.

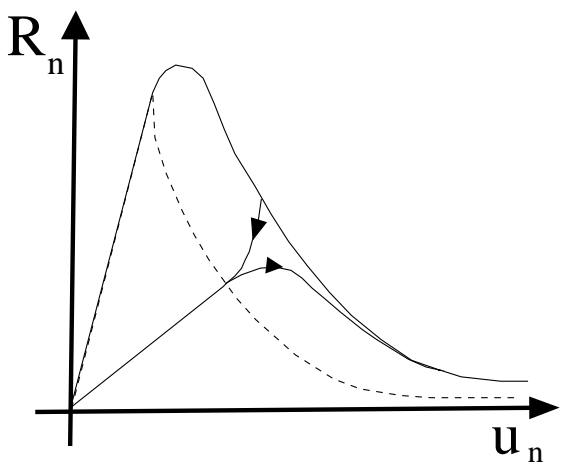

(a) Standard RCCM

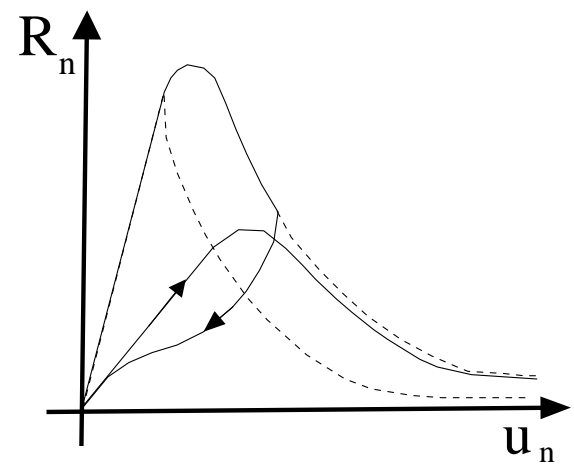

(b) RCCM with recoverable adhesion

Figure 5. Normal behavior simulated by the RCCM model including viscous dissipation

- Reversible adhesion

In a recent study, the RCCM model was extended to include recoverable adhesion [75] [80]. The intensity of adhesion, which was completely lost when the interface was widely opened, can be completely or partly recovered when the two bodies are brought into contact again. In the model developed in the thesis by Schryve [80], a new function analogous to the accumulated plasticity was introduced, in which the loading path is memorized and controls the evolution of the adhesion (see Fig. 5 (b)). This model was used to simulate the Van der Waals forces when modeling the contact between a sphere and a rubber plate. 


\section{A unified model}

An axiomatics for models describing adhesive contact between rigid bodies was recently proposed by Del Piero and Raous [22]. The loss of adhesion is assimilated here to irreversible damage, and the intensity of the damage is assumed to depend on the combined effects of the normal and tangential deformation. Unilateral conditions are prescribed on the normal components of the relative displacements and on the interface stresses. To model the friction, on the tangential components, the Coulomb law is a possible choice but more general ones can also be adopted. The intensity of friction increases gradually with the damage in order to ensure a smooth transition between the adhesive and friction regimes. The dissipation can also include a part due to the viscosity. The aim of the study in question was to model interface behavior using the smallest possible number of variables. This unified approach was based on:

- general laws, typically, energy conservation and dissipation principles, i.e., mechanical versions of the first two laws of thermodynamics,

- a set of state variables, i.e., a set of independent variables which entirely determine the response to all possible deformation processes,

- a set of elastic and dissipation potentials, which are functions of state in terms of which the general laws take specific forms,

- a set of constitutive assumptions.

The behavior of the interface is first characterized by two loading curves $f_{n}\left(u_{n}\right)$ and $f_{t}\left(u_{t}\right)$, which are assumed to be star-shaped with respect to the origin, where $u_{n}$ and $u_{t}$ are the normal and tangential components of the relative displacement at the interface and $R_{n}$ and $R_{t}$ are the respective components of the contact force.

A state variable $\alpha$ is introduced to express the current intensity of damage. This variable depends strictly on the intensity of adhesion $\beta$ introduced by Frémond [31] [32]. The use of a single state variable was based on the idea that the intensity of damage is determined by the combination of the normal and tangential effects. The variables $\left\{u_{n}, u_{t}, \alpha\right\}$ have to satisfy a set of inequalities which defines the state space. As an example, in the special case where there is no viscosity, the loading curve $R_{n}=f_{n}\left(u_{n}\right)$ and the state space corresponding to the normal components are given in Fig.6 (a) and (b). The response to a loading-unloading process starting at the origin is given in these figures by the dashed line in the force-displacement plane (a) and in the state space (b). For further details, see [22].

As described in [22], the strain energy is therefore given by :

$$
\Psi\left(u_{n}, u_{t}, \alpha\right)=\frac{1}{2} g_{n}(\alpha) u_{n}^{2}+\frac{1}{2} g_{t}(\alpha) u_{t}^{2}
$$




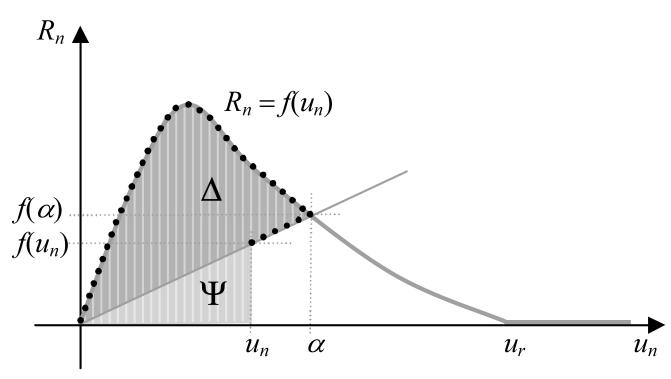

(a) force/displacement

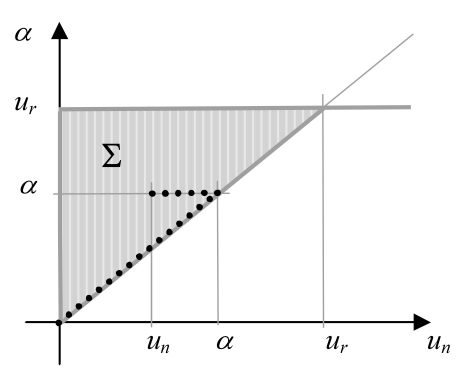

(b) State space

Figure 6. Adhesion with damage without viscosity: the normal behavior

where $g_{n}\left(u_{n}\right)=\frac{f_{n}\left(u_{n}\right)}{u_{n}}$ and $g_{t}\left(u_{t}\right)=\frac{f_{t}\left(u_{t}\right)}{u_{t}}$ are the current stiffness of the interface. The dissipation potential is then deduced from the energy balance evaluated on the force-displacement response (see Fig. 6):

$$
\Phi_{d}(\alpha, \dot{\alpha})=-\frac{1}{2}\left(g_{n}^{\prime}(\alpha)+\frac{1}{2} g_{t}^{\prime}(\alpha)\right) \alpha^{2} \dot{\alpha}
$$

This dissipation potential corresponds to the following dissipation power associated with the damage process (where $g^{\prime}$ denotes the derivative with respect to $\alpha)$ :

$$
D_{d}=-\frac{1}{2}\left(g_{n}^{\prime}(\alpha)+\frac{1}{2} g_{t}^{\prime}(\alpha)\right) \alpha^{2} \dot{\alpha} .
$$

When the viscosity is included in the evolution of the damage, a dissipation potential is added:

$$
\Phi_{v}(\alpha, \dot{\alpha})=\frac{1}{4} h(\alpha) \dot{\alpha}^{2}
$$

where $h(\alpha)$ is given and defines the viscous dependence $(h(\alpha)>0)$.

The associated dissipation power can then be written :

$$
D_{v}(\alpha, \dot{\alpha})=\frac{\partial}{\partial \dot{\alpha}} \Phi_{v}(\alpha, \dot{\alpha}) \dot{\alpha}=\frac{1}{2} h(\alpha) \dot{\alpha}^{2} .
$$

In order to account for the friction, the following friction dissipation power is added :

$$
D_{f}\left(\alpha, R_{n}^{-}, \dot{u}_{t}\right)=\mu(\alpha) R_{n}^{-}\left|\dot{u}_{t}\right|
$$

where $\mu$ is the friction coefficient, which is generally a function of $\alpha$. This is essential to be able to control progressive increase in the friction contribute which occurs as long as the intensity of adhesion decreases during the competition between the two effects.

Along with the definition of the state of admissible states for $\left(R, u_{n}, u_{t}, \alpha\right)$, the energy conservation can be written in the form of the power equation:

$$
R \dot{u}=\dot{\Psi}+D_{d}+D_{v}+D_{f}
$$


and the dissipation principles can be written

$$
D_{d} \geq 0 \quad D_{v} \geq 0 \quad D_{f} \geq 0
$$

based on the mechanical version of the Clausius Duhem inequality. Using the power equation (and its first or second derivative when the power equation is identically satisfied) and the previous inequalities, the following behavior law, including the Signorini conditions, is obtained for the interface (details can be found in [22])

$$
\begin{gathered}
R_{n}^{+}=g_{n}(\alpha) u_{n} \\
R_{n}^{-} \geq 0 \\
u_{n} \geq 0 \\
R_{n}^{-} u_{n}=0 \\
R_{t}=g_{t}(\alpha) u_{t}+\mu(\alpha) R_{n}^{-} \operatorname{sgn}\left(\dot{u}_{t}\right)
\end{gathered}
$$

and the equations for the evolution of $\alpha$ are given by

$$
\begin{cases}\dot{\alpha}=0 \quad \text { if } \quad\left(\rho(\alpha) u_{n}^{2}+(1-\rho(\alpha)) u_{t}^{2}-\alpha^{2}\right. & \text { is non-positive } \\ \dot{\alpha}=\frac{1}{\chi(\alpha)}\left(\rho(\alpha) u_{n}^{2}+(1-\rho(\alpha)) u_{t}^{2}-\alpha^{2}\right. & \text { if it is }\end{cases}
$$

where:

$$
\rho(\alpha)=\frac{g_{n}^{\prime}(\alpha)}{g_{n}^{\prime}(\alpha)+g_{t}^{\prime}(\alpha)} \text { and } \chi(\alpha)=-\frac{h(\alpha)}{g_{n}^{\prime}(\alpha)+g_{t}^{\prime}(\alpha)}
$$

A relatively simple and general model for the response of an adhesive interface was therefore obtained from the given data consisting in the functions $f_{n}$ and $f_{t}$ and the dissipation potentials involved in the viscosity and the friction. In addition to the damage, viscosity and friction, other effects can be added by introducing further appropriate potentials. More sophisticated responses can also be obtained by introducing supplementary state variables. The axiomatic framework developed by Del Piero and Raous [22] provides a flexible tool for describing a wide range of experimentally observed types of interface behavior. The laws presented in the previous section could be obtained by using appropriate forms of $f_{n}, f_{t}, h(\alpha), \mu(\alpha)$ as shown in the next section in the case of the RCCM model. 


\section{A specific case of the unified formulation: that of the RCCM model}

\subsection{The model}

The RCCM model [72] [73] can be deduced from the general model by choosing the strain energy, the dissipation potentials and the constitutive functions $f_{n}$ and $f_{t}$, appropriately. Let us take:

$$
\Psi\left(u_{n}, u_{t}, \alpha\right)=\frac{1}{2}\left(C_{n} u_{n}^{2}+C_{t} u_{t}^{2}\right) \beta^{2}
$$

where the state variable $\beta$, which is the intensity of adhesion (as defined by Frémond [31] [32]) is related to the previous state variable $\alpha$ as follows:

$$
\beta=\frac{\omega}{\left(C_{n}+C_{t}\right) \alpha^{2}}=\frac{\omega^{*}}{\alpha^{2}}
$$

where $C_{n}$ and $C_{t}$ are the initial normal and tangential stiffness of the interface and $\omega$ is the adhesion energy.

The functions $f_{n}\left(u_{n}\right), f_{t}\left(u_{t}\right), h(\alpha)$ and $\mu(\alpha)$ are defined as follows:

$$
\begin{gathered}
f_{n}\left(u_{n}\right)=C_{n} \frac{\omega^{* 2}}{u_{n}^{3}} \quad \text { and } \quad f_{t}\left(u_{t}\right)=C_{t} \frac{\omega^{* 2}}{u_{t}^{3}}, \\
h(\alpha)=8 b \frac{\omega^{* 2}}{\alpha^{6}} \text { and } \mu(\alpha)=\left(1-\omega^{*} \alpha^{-2}\right) \mu
\end{gathered}
$$

where $b$ is the viscosity parameter. The dissipation potentials are defined as follows:

$$
\begin{gathered}
D_{d}(\beta)=-\omega \dot{\beta} \text { and then } \dot{\beta} \leq 0 \text { (irreversibility of the damage) } \\
\qquad \begin{array}{c}
D_{v}(\beta)=b \dot{\beta}^{2} \\
D_{f}\left(R_{n}, u_{n}, \beta, \dot{u}_{t}\right)=(1-\beta) \mu\left(R_{n}-C_{n} u_{n} \beta^{2}\right)\left|\dot{u}_{t}\right| .
\end{array}
\end{gathered}
$$

With these choices, we obtain the following RCCM constitutive law [73], which is written here in the two-dimensional case as follows:

where

$$
\begin{gathered}
R_{n}^{-} \geq 0 \quad u_{n} \geq 0 \quad R_{n}^{-} u_{n}=0 \\
\left|R_{t}-\beta^{2} C_{t} u_{t}\right| \leq \mu(1-\beta)\left|R_{n}^{-}\right|
\end{gathered}
$$

$$
\begin{gathered}
\text { if }\left|R_{t}-\beta^{2} C_{t} u_{t}\right|<\mu(1-\beta)\left|R_{n}^{-}\right| \quad \text { then } \quad \dot{u}_{t}=0 \\
\text { if }\left|R_{t}-\beta^{2} C_{t} u_{t}\right|=\mu(1-\beta)\left|R_{n}^{-}\right| \quad \text { then } \exists \lambda \geq 0 \quad \dot{u}_{t}=-\lambda\left(R_{t}-\beta^{2} C_{t} u_{t}\right)
\end{gathered}
$$




$$
\dot{\beta}=-\frac{1}{b}\left(\omega-\beta\left(C_{n} u_{n}^{2}+C_{t}\left|u_{t}\right|^{2}\right)^{-}\right.
$$

and where the constitutive parameters are the friction coefficient $\mu$, the initial stiffness of the interface $C_{n}$ and $C_{t}$, the adhesion energy $\omega$ (which acts as a threshold in (27))and the viscosity of the interface $b$. The corresponding graphs are given in Fig.5 (a) and Fig. 4 (a).

\subsection{Variational formulation and solvers for the RCCM model}

\subsubsection{Quasi-static problems}

In cohesive zone models, where the friction is not usually taken into account, the global formulation and the numerical methods used so far are very similar to those used with volumic damage in the literature. In adhesive models where the adhesion is combined with the friction and the unilateral conditions, the framework is very similar to that adopted in the case of friction contact problems. The additional problem arising here is how to evaluate and compute the evolution of the intensity of adhesion, and how to deal with the softening effects. The difficulties encountered here are therefore basically those associated with the non smooth character of the problem when neither regularization nor penalization procedures are used. The strict non penetration condition (Signorini conditions) means that the behavior law in the normal direction is a multivalued application and no longer a function. The quasi-static formulation associated with the RCCM model is given in [73] under the form of two variational inequalities (one of which is implicit), along with a differential equation giving the evolution of the intensity of adhesion $\beta$.

Some mathematical results can be found in Cocou et al [15] [17].

Various solvers have been implemented in the finite element code GYPTIS at the LMA. Some of these solvers were based on a fixed point method on the sliding limit, which leads to a sequence of minimization problems under constraints of a non differentiable functional (Over-relaxation with projection, projected Gauss-Seidel with Aitken acceleration, projected Conjugate Gradient [70]). Another solver, which was used here, is the Lemke algorithm, a mathematical programming method. Details can be found in the CISM course [71].

Among the other approaches to this problem, Talon and Curnier [83] give algorithms based on either a penalty approximate or an augmented Lagrangian method.

For quasi-static problems, the RCCM model was used at the LMA in the field of composite materials (fiber-matrix interface [72] [73] [11] [57]) and in the field of Civil Engineering to deal with problems involving reinforced concrete [76], pile-soil interface [84] and masonry [1] [29] [77]. 


\subsubsection{Dynamic problems}

When these problems are addressed without using any regularization procedures, the dynamics has to be written in terms of non-smooth dynamics which has been studied in details by J.-J. Moreau [59]. Because of the discontinuities in the velocities, the dynamics has to be expressed using differential measures. A numerical method developed by Jean and Moreau [42], the Non Smooth Contact Dynamics method (NSCD), was subsequently implemented in the finite element code LMGC [24]. The RCCM model has been implemented in the computer code LMGC by Jean, Monerie and Acary [43]. To give only a few examples of dynamic problems involving adhesion which have been addressed at the LMA, it is worth mentioning the studies on crack propagation in composite materials in which the behavior of the fiber/matrix interfaces is taken into account [58] [55] [74] or the behavior of masonry-like structures subjected to dynamic loading forces simulating an earthquake [43]. In the field of Geophysics, the RCCM model is used in [27] [28] to simulate the nucleation process where two semi-infinite half-planes are pressed together and subjected to a given perturbation (based on a simple model for the nucleation of an earthquake [90]). The propagation of the super-shear waves involved was computed using a spectral computer code.

\section{Open problems and ongoing researches}

Many studies are currently under way on the use of cohesive zone models for simulating crack propagation, whether or not the direction of the crack is known. More accurate models are now required for simulating complex interfaces in various fields ranging from nano-mechanics to geophysics and from structure and material mechanics to civil engineering. Among these developments, some fundamental questions still remain to be answered or have only been partly solved. Here, we will take a brief look at some of these points.

\subsection{Theoretical problems about the uniqueness of solutions and instabilities}

Because of the lack of convexity and the softening character of these laws, uniqueness of the solutions is not ensured, and jumps or instabilities can occur during quasi-static loading process. In [55] [56] [1], a condition for uniqueness is given and illustrated in the case of a simple uni-axial example, where it is established that the uniqueness condition depends on the relative values of the stiffness of the structure and the slope of the weakening part of the cohesive graph. The instability, in the sense of the possibility of the occurrence of jumps, is greater when the slope of the weakening part increases. It has been 
noted that the shape of the cohesive graph has practically no effect on the stationary propagation of a cohesive crack, although the crack initiation and the jumps in the solution depend strongly on this parameter.

It has also been noted that relating the normal and tangential effects tends to increase the instability, and this is the case when friction is considered.

Uniqueness and stability have also been closely studied by J.-J. Marigo et al [50]; in [14], the stability properties related to a Griffith's criterion and a Barenblatt cohesive model were compared in the framework of variational approaches.

It is worth noting that the presence of viscosity in the model, as it is the case in the RCCM model, reduces the instability and the occurrence of jumps (the slope of the weakening part is smaller).

In the general case, the solutions have to be evaluated using a dynamic formulation in order to account satisfactorily for the behavior of the structure when these jumps occur.

Existence and approximation results have been given in Cocou et al [15] [16] [18] for the problems set with the strict Signorini and Coulomb conditions. Quasi-static and dynamic problems have been addressed in this context.

\subsection{Non local damage}

Another regularization procedure consists in considering non local damage, using a second gradient formulation to simulate the interface damage. Although considering adhesion to result from a non local event makes sense from the mechanical point of view, it should be noted that non local adhesion has mainly been introduced for regularizing purposes. In the space discretization, it regularizes the localization of the deformation and may render numerical analyses mesh-objective (Peerling et al [69] [68] in the case of quasi-brittle materials and concrete fracture, as in the study by Geers et al [35] on fracture in short glass-fibre reinforced propylene). In the time evolution, it can reduce the presence of jumps in the solution (Freddi and Fremond [30], Peerings et al [69]). Frémond was one of the first authors to develop models of this kind such as that developed with Nedjar in the case of volumic damage [34]. In Freddi and Frémond [30] a delamination experiment on a fiber-reinforced polymer (FRP) composite was simulated using a model in which the gradient of the damage was taken into account. In that study, including the damage in the volume made it possible to simulate of the ruptures in the vicinity of the adhesive interface.

Lorentz [48] [49] has also used a non local damage approach to studying crack propagation and has discussed the model in terms of an internal length defined by the parameters involved in the contribution of the damage gradient. Non local damage models combined with plasticity have also been discussed in Cazes et al [12] [13]. A synthesis on gradient of damage enhancement in 
interface models will be found in [92].

\subsection{Cohesive zone model and usual failure criteria}

Many comparisons have been made between classical criteria, such as the Griffith criterion, and cohesive zone models. Marigo and Truskinovsky [50] have shown, for example, that the Barenblatt model tends towards the Griffith model (in the sense of $\Gamma$-convergence) when the ratio between the external and internal length increases indefinitely. In a series of papers, Jaubert, Marigo and Abdelmoula [38] [4] [3] recently demonstrated how to draw up a Paris-type fatigue law from Dugdale-Barenblatt models.

These comparisons are still a matter of debate for studying crack propagation in an unknown solid without any pre-defined crack direction, and for analyzing the stability as mentioned above.

\subsection{Cohesive zone models and finite element discretization}

Some dependence of the solutions of cohesive models on the meshes has been observed and some relationships have been evaluated between the characteristic length of the model and the size of the mesh elements (see for example Espinosa and Zavaretti [26]).

When a cohesive zone model is used to study crack propagation in situations where the direction of the crack is not given a priori, the solution is highly mesh dependent (Tijssens et al [86].

Special attention is being paid by other authors to problems of convergence with mesh refinement (see Lorentz [48] using a multivalued cohesive law).

In order to simulate delamination at brittle interfaces such as those frequently present in microelectronics and to control the jumps liable to occur in the solutions, a specific enriched finite element has been developed by Samimi et al [79].

Some alternative approaches are also being developed. In a recent study, Moes et al [54] presented a thick level set (TLS) approach to damage growth as an alternative to the use of cohesive zone models. The computations were carried out with X-FEM methods, which has been also used by Cazes in a study on cohesive models in the case of large displacements.

\subsection{Asymptotic contact laws}

One possible alternative approach to the interface models previously presented consists in developping models based on the mechanical behavior of a thin layer 
in a micro-macro process. Various linear and non linear behavior of the thin layer have been considered: elastic, viscoelastic and elastoplastic behavior, non monotonous behavior, etc. The asymptotic contact laws are then obtained by applying an asymptotic method considering two small parameters : the thickness and the rigidity. The first theoretical and mathematical results on these lines were obtained by Licht-Michaille in various studies published during the last fifteen years (see for example [47]). Other studies have focused on the non linearities involved in the thin layer behavior, the numerical developments and applications of this approach (see Lebon et al [45] [44]).

\section{References}

[1] Acary, V., Monerie, Y., 2006. Nonsmooth fracture dynamics using a cohesive zone model, INRIA report n6032, 56 pages (ISSN 0249-6399)

[2] Allix, O., Ladevèze, P., Corigliano, A., 1995. Damage analysis of interlaminar fracture specimens. Composite Structures 31(1), 61-74.

[3] Abdelmoula, R., Marigo, J.-J., Weller, Th., 2009. Contruction d'une loi de fatigue à partir d'un modèle de forces cohésives: cas des fissures en mode III, C.R. Mecanique, 337, 53-59.

[4] Abdelmoula, R., Marigo, J.-J., Weller, Th., 2009. Contruction d'une loi de fatigue à partir d'un modèle de forces cohésives: cas des fissures en mode I, C.R. Mecanique, 337, 166-172.

[5] Alfano, G., Sacco, E., 2006. Combining damage and friction in a cohesive-zone model, Int. J. Num. Meth. Engn. 65, 542-582.

[6] Barenblatt, G.I., 1962. The mathematical theory of equilibrium cracks in brittle fracture. Adv. Appl. Mechanics 7, 55-129.

[7] Barquins, M., 1992. Adherence, friction and wear of rubber-like materials. in: Wear and friction of elastomers, R. Denton and M.K. Keshavan (Eds), American Society for Testing and Materials, Philadelphia, 82-113.

[8] van der Bosch, M.J., Schreurs, P.J.G., Geers, M.G.D., 2007. A cohesive zone model with a large displacement formulation accounting for interfacial fibrilation. Eur. J. Mech. A/Solids 26, 1-19.

[9] Brinckmann, S., Siegmund Th., 2008. A cohesive zone model based on the micromechanics of dislocations. Modelling Simul. Mater. Sci. Eng. 16, 19p.

[10] Campillo, M., Ionescu, I. R., 1997. Initiation of antiplane shear instability under slip dependent friction, J. Geophys. Res. 102 (B9), 20363-20371.

[11] Cangémi, L., 1997. Frottement et adhérence: modèle, traitement numérique et application à l'interface fibre/matrice. Thesis, M. Raous (Adv.), Univ. Provence.

[12] Cazes, F., Coret, M., Combescure, A., Gravouil, A., 2009. A thermodynamic method for the construction of a cohesive law from a non local damage model, Int. J. Solids Struct., 46 (6), 1476-1490. 
[13] Cazes, F., Simatos, A., Coret, M., Combescure, A., 2010. A cohesive zone model which bis energetically equivalent to a gradient-enhanced coupled damageplasticity model, Eur. J. Mech. A/Solids, in press.

[14] Charlotte, M., Laverne, J., Marigo, J.-J., 2006. Initiation of cracks with cohesive force models: a variational approach, Eur. J. Mech. A/Solids, 25, 649-669.

[15] Cocou, M., Cangemi, L., Raous M., 1999. Approximation results for a class of quasistatic contact problems including adhesion and friction, in: Proc. IUTAM Symposium on Variations de Domaines et Frontières Libres en Mécanique des Solides, P. Argoul, M. Frémond, Q.S. Nguyen (Eds), Kluwer, 211-218.

[16] Cocou, M., Rocca, R., 2000. Existence results for unilateral quasistatic contact problems with friction and adhesion, Math. Model. Num. Anal. 34(5), 981-1001.

[17] Cocou M., Raous, M., 2002. Adhesive contact and implicit evolution variational inequalities, in: Nonsmoooth/Nonconvex Mechanics with Applications in Engineering - In memoriam of Prof. P.D. Panagiotopoulos, C.C. Baniotopoulos (eds.), Ziti Publisher, 167-174.

[18] Cocou, M., Schryve, M., Raous, M., 2010. A dynamic unilateral contact problem with adhesion and friction in viscoelasticity, ZAMP 61, 721-743.

[19] Chaboche, J.-L., Feyel, F., Monerie, Y., 2001. Interface debonding model: a viscous regularization with a limited rate dependency. Int. J. Solids Structures 38(18), 3127-3160.

[20] Costanzo, F., Walton, J.R., 1997. A study of dynamic crack growth in elastic materials using a cohesive zone model. Int. J. Engng. Sci. 35(12-13), 1085-1114.

[21] De Boorst, R., Remmers, J.J.C., Needlman, A., 2006. Mesh-independent discrete numerical representation of cohesive-zone models, Engineering Fracture Mechanics, 73, 160-177.

[22] Del Piero, G., Raous, M., 2010. A unified model for adhesive interfaces with damage, viscosity, and friction, European Journal of Mechanics A/Solids, 29, 496-507.

[23] Dieterich, J.H., 1978. Time dependant friction and the mecchanics of stick-slip, Pure Appl. Geophys., 116 (4-5), 790-806.

[24] Dubois, F., Jean, M. , 2003. Une plateforme de développement dédiée la modélisation des problèmes d'interaction. In: Potier-Ferry M., Bonnet M., Bignonnet A. (Eds). Proc VI Coll. Nat. Calcul de Struct. V1, Giens, 111-118.

[25] Dugdale, D.S., 1960. Yielding of steel sheets containing slits. J. Mech. Phys. Solids 8, 100-104.

[26] Espinosa, H.D., Zavattieri, P.D., 2003. A grain level model for the study of failure initiation and evolution in polycrystalline brittle materials, Part 1: Theory and numerical implementation, Mechanics of Materials, 35, 333-364.

[27] Festa, G., Vilotte J.-P., Raous, M., Henninger, C., 2010. Scale-Dependent Friction and Damage Interface law: implications for effective earthquake rupture dynamics and radiation, Geophysical Research Abstracts (EGU2010) 12, 11647. 
[28] Festa, G., Vilotte, J.-P., Raous, M., in preparation. Nucleation length in an adhesive-frictional interface under nonuniform fault loading condition.

[29] Fouchal, F., Lebon, F., Titeux, I., 2009. Contribution to the modelling of interfaces in masonry construction, Constr. Build. Materials 23, 6, 2428-2441.

[30] Freddi, F., Frémond, M., 2006. Damage in domains and interfaces : a coupled predictive theory, J. Mech. Mat. Structures 1(7), 1205-1234.

[31] Frémond, M., 1987. Adhérence des solides. J. Méc. Théor. Appl. 6 (3), 383-407.

[32] Frémond, M., 1988. Contact with adhesion, in: Moreau, J.-J., Panagiotopoulos, P.D. (Eds.), Nonsmooth Mechanics and Applications, CISM Courses and Lectures, 302, Springer, Wien, 177-221.

[33] Frémond, M., 2001. Non-smooth thermodynamics, Springer-Verlag, Heidelberg.

[34] Frémond, M., Nedjar, B., 1996. Damage, gradient of damage and principle of virtual power, Int. J. Solids Structures 8, 1083-1103.

[35] Geers, M.G.D., de Borst, R., Brekelmans, W.A.M., Peerlings, R.H.L., 1999. Validation and internal length scale determination for a gradient damage model: application to short glass-fibre-reinforced polypropylene, Int. J. Solids Struct. $36,2557-2583$.

[36] Goryacheva, I., Makhovskaya, Y., 2088. Adhesion effects in contact interaction of solids, C.R. Mecanique 336, 118-125.

[37] Greenwood, J.A., 1997. Ahesion of elastic spheres, Proc. Royal Soc. London A 453, 1277-1297.

[38] Jaubert, A., Marigo, J.-J., 2006. Justification of Paris-type fatigue laws from cohesive forces model via a variational approach, Continuum Mech. Thermodyn, $18,23-45$.

[39] Johnson, K.L., Kendall, K., Roberts, A.D., 1971. Surface energy and the contact of elastic solids. Proc. Royal Soc. London A 324, 301-313.

[40] Jonhson, K.L., Pollock, H.M., 1994. The role of adhesion in the impact of elastic spheres. J. Adh. SCi. Techn. 8, 1323-1332.

[41] Jonhson, K.L., Contact mechanics, Cambridge university Press, 1985.

[42] Jean, M., 1999. The Non Smooth Contact Dynamics method, Computer Meth. Appl. Mech. and Engrg. 177(3-4), 235 - 257.

[43] Jean, M., Acary, V., Monerie, Y., 2001. Non Smooth Contact dynamics approach of cohesive materials. In: Philosophical Transactions: Mathematical, Physical Engineering Sciences, Royal Society, London A359(1789), 2497-2518.

[44] Lebon, F., Ould Khaoua, A., Licht, C., 1998. Numerical study of soft adhesive bounded joints in finite elasticity, Comput. Mechanics 21, 134-140.

[45] Lebon, F., Rizzoni, R., Ronel-Idrissi, S., 2004. Asymptotic analysis of some non-linear soft thin layers, Comp. Struct. 82, 1929-1938.

[46] Lemaitre, J., 1992. Formulation de l'endommagement des interfaces, CRAS 315 (série II), 1047-1050. 
[47] Licht, Ch., Miraille, G., 1997. A modelling of elastic adhesive bonded joints, Adv. Math. Sci. Appl. 7, 711-740.

[48] Lorentz, E., 2008. A mixed inteface finite element for cohesive zone models, Comput. Methods Appl. Mech. Engrg., 198, 320-317.

[49] Lorentz, E., Cuvilliez, S., Kazymyrenko, K., submitted. Convergence of a gradient damage model toward a cohesive zone model.

[50] Marigo, J.-J., Truskinovsky, L., 2004. Initiation and propagation of fracture in the models of Griffith and Barenblatt, Cont. Mech. Thermdyn., 16, 391-409.

[51] Maugis, D., 1992. Adhesion of spheres : the JKR-DMT transition using a Dugdale model, J. Colloid Interf. Sci. 150, 243-269.

[52] Maugis, D., Barquins, M., 1980. Fracture mechanics and adherence of viscoelastic solids, in: Adhesion and Adsorption of Polymers (part A), L.H. Lee (Ed), Plenum press, New-York, 20-277.

[53] Michel, J.C., Suquet, P., 1994. Analytical and numerical study of the overall behaviour of metal-matrix composites. Model. Simul. Mater. Sci. Eng. 2, 637658.

[54] Moës, N., Stolz, C., Bernard, P.-E., Chevaugeon, N., 2010, A level set based model for damage growth: the thick level set approach, Int. J. Numer. Meth. Engng, to appear, 30 pages.

[55] Monerie, Y., 2000. Fissuration des matériaux composites: rôle de l'interface fibre/matrice. Thesis, M. Raous (Adv.), Univ. Provence.

[56] Monerie, Y., Acary, V., 2001. Formulation dynamique d'un modèle de zone cohésive tridimensionnelle couplant endommagement et frottement, Revue Européenne des Eléments Finis, 10, 489-504.

[57] Monerie, Y., Raous, M., Leroy, F.H., Suder, O., Feyel, F., Chaboche, J.-L., 1998. Comparaison de lois d'interface fibre/matrice sur la base d'un modèle uniaxial d'expérience de micro-indentation, in Proceedings $11^{i e ̀ m e}$ Journées Nationales sur les Composites, J. Lamon, D. Baptiste (Eds), t.2, AMAC Publish., 565-574.

[58] Monerie, Y. and Raous, M., 2000. A model coupling adhesion to friction for the interaction between a crack and a fiber/matrix interface, Zeitschrift für Angewandte Matematik und Mechanik, Special Issue, 80, 205-209.

[59] Moreau, J.-J., 1988. Unilateral contact and dry friction in finite freedom dynamics, in: Non Smooth Mechanics and Applications, J.J. Moreau and P.D. Panagiotopoulos (Eds), CISM Courses and lectures 302, Springer-Wien, 1-82.

[60] Needleman, A., 1987. A continuum model for void nucleation by inclusion debonding. J. Appl. Mech. 54, 525-531.

[61] Needleman, A., 1990. An analysis of tensile decohesion along an interface. J. Mech. Phys. Solids 38(3), 289-324.

[62] Needleman, A., 1992. Micromechanical modeling of interfacial decohesion. Ultramicroscopy, 40, 203-214. 
[63] Needleman, A., Rosakis, A.J., 1999. The effect of bond strength and loading rate on the conditions governing the attainment of intersonic crack growth along interfaces. J. Mech. Phys. Solids 47, 2411-2449.

[64] Nguyen, C., Levy, A.J., 2009. An exact theory of interfacial debonding in layered elastic composites. Int. J. Solids Structures 46, 2712-2723.

[65] Ozemir, I., Brekelmans, W.A.M., Geers, M.G.D., 2010. A thermo-mechanical cohesive zone model. Comput. Mech. 46, 735-745.

[66] Palmer, A.C. and Rice, J.R., 1973. The growth of slip surfaces in the progressive failure of over-consolidated clay. Proc. Roy. Soc. Lond. A. 332, 527-548.

[67] Péralès, F., 2005. Fissuration des matériaux à gradient de propriétés. Application au Zircaloy hydruré. Thesis, Chrysochoos-Monerie (Adv.), Univ. Montpellier II.

[68] Peerlings, R.H.J., de Borst, R., Brekelmans, W.A.M., de Vree, J.H.P., 1996. Gradient enhaced damage for quasi-brittle materials, Int. J. Numer. Meth. Engn. 39, 3391-3403.

[69] Peerlings, R.H.J., de Borst, R., Brekelmans, W.A.M., Geers, M.G.D., 1998. Gradient-enhanced damage modelling of concrete fracture, Mech. Cohes.-Frict. Mater. 3, 323-342.

[70] Raous, M., Barbarin, S., 1992. Preconditioned conjugate gradient method for a unilateral problem with friction, in: Contact Mechanics, A. Curnier (Ed), Press. Polytech. et Univ. Romandes, 423-432.

[71] Raous, M., 1999. Quasistatic Signorini problem with Coulomb friction and coupling to adhesion, in: New Developments in Contact Problems, WriggersPanagiotopoulos (Eds), CISM Courses \& Lect., 384, Springer Verlag, Wien, 101-178.

[72] Raous, M., Cangémi L., Cocou M. 1997. Un modèle couplant adhérence et frottement pour le contact entre deux solides déformables, CRAS, 325(9), Série II b, 503-509.

[73] Raous, M., Cangémi L., Cocou M., 1999. A consistent model coupling adhesion, friction and unilateral contact. Comput. Methods in Appl. Mech. Engrg. 177, 383-399.

[74] Raous, M., Monerie, Y., 2002. Unilateral contact, friction and adhesion in composite materials, in: Contact Mechanics, Martins-Monteiro Marques (Eds),Kluwer, Dordrecht, 333-346.

[75] Raous, M., Schryve, M., Cocou, M., 2006. Restorable adhesion and friction, in: Nonsmooth/Nonconvex Mechanics with Applications in Engineering, Baniotopoulos (Ed.), Ziti Publisher, Thessaloniki, 165-172.

[76] Raous, M., Karray, M.A., 2009. Model coupling friction and adhesion for steelconcrete interfaces, Int. J. Comput. Appl. Techn. 34(1), 42-51.

[77] Rekik, A., Lebon, F., 2010. Identification of the representative crack length evolution in a multi-level interface model for quasi-brittle masonry, Int. J. Solids Struct. 47, 3011-3021. 
[78] Rice, J.R., Ruina A.L., 1983. Stability of steady frictional slipping. J. Appl. Mech., 50, 343-349.

[79] Samimi, M., van Dommelen, J.A.W., Geers, M.G.D., 2009. An enriched cohesive zone model for delamination in brittle interface. Int. J. Numer. Meth. Engn 80, 609-630.

[80] Schryve, M., 2000. Modéle dadhésion cicatrisante et applications au contact verre/élastomére. Thesis, Raous-Cocou (Adv.), Univ. Provence.

[81] Sheng, D., Wriggers, P. and Sloan S.W., 2007. Application of Frictional Contact in Geotechnical Engineering, Int. J. Geomechanics May-June, 176-185.

[82] Sperling, G., 1964. Eine Theorie der Haftung von Feststoffteilchen an festen Korpern. Dissertation von der Facultat fur Machinenwesen der Technischen Hochschule Karlsuhe.

[83] Talon, C., Curnier, A., 2003. A model of adhesion coupled to contact and friction. Eur. J. Mechanics A/Solids 22, 545-565.

[84] Terfaya, N., Raous, M. and Berga A., 2010. Cohesive zone model and bipotential formulation : application to a pile/soil interface, in Proceedings 3rd Euro Mediterranean Symposium on Advances in Geomaterials and Structures, 6p.

[85] Stupkiewicz, S., 1996. Fiber sliding model accounting for interfacial microdilatancy, Mech. Materials 22, 65-84.

[86] Tijssens, M.G.A., Sluys, L.J., van der Giessen, E., 2000. Numerical simulation of quasi-brittle fracture using damaging cohesive surface, Eur. J. Mech. A/Solids, 19, 761-779.

[87] Tvergaard, V., 1990. Effect of fibre debonding in a wisker-reinforced metal. Mat. Sci. Engrg. A125, 203-213.

[88] Tvergaard, V., Hutchinson, J.W., 1992. The relation between crack growth resistance and fracture process parameters in elastic-plastic solids. J. Mech. Phys. Solids 40, 1377-1397.

[89] Tvergaard, V., Hutchinson, J.W., 1996. Effects of strain-dependent cohesive zone model on prediction of crack growth resistance. Int. J. Solids Structures. $33,3297-3308$.

[90] Uenishi, K., Rice J. R., 2003. Universal nucleation length for slip-weakening rupture instability under non uniform fault loading, J. Geophys. Res. 108 (B1), 2042, doi:10.1029/2001JB001681.

[91] Valoroso, N., Champaney, L., 2006. A damage-mechanics-based approach for modelling decohesion in adhesively bonded assemblies, Engineering Fracture Mechanics 73 (18), 2774-2801.

[92] Valoroso, N., Raous, M., in preparation. Gradient of damage enhancement for an interface model.

[93] Xu, X.-P., Needleman, A., 1994. Numerical simulations of fast crack growth in brittle solids. J. Mech. Phys. Solids 42(9), 1397-1434. 